SLEEP DISORDERED BREATHING

\title{
Comparison of three ways to determine and deliver pressure during nasal CPAP therapy for obstructive sleep apnoea
}

\author{
S D West, D R Jones, J R Stradling
}

See end of article for authors' affiliations

Correspondence to: Dr S D West, Oxford Centre for Respiratory Medicine, Churchill Hospital, 'Headington, Oxford OX3 7ப, UK sophie@west66.freeserve. co.uk

Received 8 May 2005 Accepted 4 October 2005 Published Online First 27 October 2005

\begin{abstract}
Background: The simplest method of initiating and maintaining therapeutic continuous positive airways pressure (CPAP) therapy for obstructive sleep apnoea (OSA) has not been established.

Methods: Ninety eight subjects with OSA requiring CPAP treatment (more than 10 dips in oxygen desaturation of $>4 \%$ per hour of sleep study and Epworth Sleepiness Score (ESS) $>9$ ) were randomised prospectively to three different methods of CPAP delivery for 6 months: (1) autotitration pressure throughout; (2) autotitration pressure for 1 week followed by fixed pressure (95th centile) thereafter; and (3) fixed pressure determined by algorithm (based on neck size and dip rate). Patients and investigators were blind to group allocation. One week after initiation the patients were routinely reviewed by sleep nurses. Study assessments took place before starting CPAP treatment and 1 and 6 months after to assess ESS, maintenance of wakefulness test, 24 hour blood pressure, general health (SF-36), and sleep apnoea related quality of life. CPAP internal monitoring data were also collected.

Results: There were no significant differences in any of the outcome measures or CPAP monitoring data between the three groups. The 95th centile CPAP pressures delivered in the 6 month and 1 week autotitration groups were higher than in the algorithm group, but the median pressures were lowest in the 6 month autotitration group.

Conclusions: The method of determining CPAP pressure for treatment of moderate to severe OSA makes no significant difference to clinical outcome measures. The autotitration CPAP machine used has no advantage in this setting over simpler methods of pressure determination.
\end{abstract}

Abbreviations: $\mathrm{AHI}$, apnoea-hypopnoea index; $\mathrm{CPAP}$, continuous positive airway pressure; ESS, Epworth Sleepiness Score; MWT, Maintenance of Wakefulness test; OSA, obstructive sleep apnoea; PTT, pulse transit time; SAQLI, Sleep Apnea Quality of Life Index 


\section{METHODS \\ Subject selection}

Subjects were identified at the outpatient Oxford Sleep Clinic between January 2002 and March 2003. Those aged 1875 years with excessive daytime sleepiness (Epworth Sleepiness Score >9) and proven OSA on a one night respiratory polysomnography sleep study were considered eligible. The one night sleep studies took place in hospital rooms that were decorated and furnished to resemble an ordinary bedroom. Body movements, heart rate, and pulse transit time (PTT) changes were recorded as measures of arousal from sleep. The PTT signal and body movements derived from video recordings are robust markers of arousal. ${ }^{12}$ Arterial oxygen saturation measurements, snoring, and increases in the respiratory swing in PTT were used as markers of breathing pattern and respiratory effort (Win-Visi Monitoring System, Stowood Scientific Instruments, Oxford, UK). The PTT swing is a sensitive index of respiratory effort that accurately predicts changes in pleural pressure and differentiates between central and obstructive apnoeas. The results of the sleep study were scored automatically with manual review to ensure the accuracy of the data. OSA was diagnosed from a review of all the data. The severity of the sleep apnoea was then quantified as the number of dips in oxygen saturation of more than $4 \%$ for every hour of the study. This index is one of the best predictors of the therapeutic response to nasal CPAP. ${ }^{12} \mathrm{~A}$ recent study has also shown that oximetry is at least as good as conventional EEG based polysomnography in predicting the response to CPAP. $^{13}$

Subjects with more than 10 dips per hour in the arterial oxygen saturation $\left(\mathrm{SaO}_{2}\right)$ of $>4 \%$ confirmed as being caused by upper airway obstruction were eligible for inclusion in the study. All were CPAP naïve. Subjects were recruited up to the capacity of the study each week, with preference for more local residents to reduce travelling times. Subjects who had respiratory failure requiring urgent treatment and those who declined to participate or could not give written informed consent were excluded from the study. Subjects were not excluded on the basis of other co-morbidities. A total of 633 patients with OSA were started on CPAP during the recruitment period. There is no reason to believe that those selected for the study were not representative of the patients seen at our clinic.

The Central Oxford research ethics committee approved the study (C02.282). This study was independent of previous studies performed in our department.

\section{Outcome measurements}

Study assessments were made before the start of CPAP and 1 and 6 months after initiating CPAP treatment.

\section{Sleepiness measures}

Subjective sleepiness was measured by means of the Epworth Sleepiness Score (ESS), an eight point self-completed questionnaire assessment of the tendency to fall asleep during various daytime situations. ${ }^{14}$ A higher score (up to 24) indicates more sleepiness. Objective sleepiness was measured by a modification of the Maintenance of Wakefulness test (MWT; OSLER), a behavioural sleep resistance challenge in which the patient is required to stay awake in a darkened sound protected room. ${ }^{15}$ The time taken to fail repeatedly to respond to a visual signal is measured, so a lower score indicates more sleepiness. ${ }^{16}{ }^{17}$ Each subject completed a single OSLER test at the same time of day on each visit after a quiet period of filling in questionnaires with the investigator (approximately 30 minutes).
Self-reported health status

Subjects completed the Short Form-36 and Sleep Apnea Quality of Life Index (SAQLI) questionnaires. The SF-36 questionnaire has been used to measure decreased quality of life in several disorders including OSA, and shows large improvements following CPAP therapy, especially the Energy and Vitality dimension which we report here. ${ }^{18}$ The SAQLI questionnaire is a disease-specific quality of life measure which records the key elements of sleep apnoea and has been used as a measure of outcome in clinical trials related to sleep apnoea. ${ }^{19}$ The minimal important difference in the total SAQLI score measured in patients using CPAP for 4 weeks has been found to be approximately 1 , a moderate difference is approximately 2, and a large difference is approximately $3 .{ }^{20}$ Scoring of the SAQLI was based on the manual by Flemons and Reimer. ${ }^{21}$

\section{Blood pressure}

Subjects were fitted with an ambulatory blood pressure monitor for 24 hours as outpatients during normal activities (TM2420, 2421, Takeda A\&D, Japan). It was programmed for cuff inflation measurements every 30 minutes throughout the 24 hour period including sleep time. By averaging the 48 readings, 24 hour mean systolic and diastolic pressures were obtained. A single mean blood pressure was calculated from this (one third of the systolic pressure plus two thirds of the diastolic pressure).

\section{CPAP data}

When patients returned for repeat study assessments their CPAP machines were downloaded to give the following data: usage (hours CPAP used per 24 hours measured as mask-on time on nights worn and number of nights used); treatment pressure (over the time period during mask-on time: 95th centile and median values); AHI; and mask leakage (net airflow greater than mask vent flow during mask-on time: 95th centile and median values; a 95th centile leak of $<0.4 \mathrm{l} / \mathrm{s}$ was considered acceptable).

\section{CPAP administration}

CPAP was administered to all patients using identical machines (Autoset Spirit, ResMed). In most patients CPAP was first used overnight at home following an afternoon training and induction session. In six patients CPAP was initiated in hospital overnight, where they received their CPAP mode according to the study group to which they had been allocated. Both these methods of CPAP initiation are available in our centre and are used according to availability.

One week after CPAP initiation the patients were routinely seen in the nurse-led CPAP clinic by personnel not involved in the study assessments. The CPAP machines were downloaded to give usage, mask leakage, pressure, and AHI data. These data were available to the sleep nurses for all patients so they could give advice and make mask adjustments according to the leakage data as necessary. All patients receiving autotitration pressure for 1 week were converted to a fixed pressure determined from their 95 th centile value over the preceding week. The nurses gave no information to the patients regarding their treatment group.

If patients had problems after the 1 week visit they were instructed to telephone the sleep nurses for advice, as is standard practice in our unit. All these calls were logged. If any patients remained symptomatic from OSA with continued snoring, the nurses were advised to increase the fixed CPAP pressure in accordance with their standard practice.

\section{Study design}

Patients attended for baseline tests before commencing CPAP therapy. Following the completion of their initial tests, 
Table 1 Median (5th/95th centile) baseline characteristics of patients entering the study according to subsequent group allocation

\begin{tabular}{lllll}
\hline & $\begin{array}{l}\text { Group 1: } \\
\text { 6 months autotitration } \\
(\mathbf{n}=31)\end{array}$ & $\begin{array}{l}\text { Group 2: } \\
\mathbf{1} \text { week autotitration } \\
(\mathbf{n}=33)\end{array}$ & $\begin{array}{l}\text { Group 3: } \\
\text { Algorithm } \\
(\mathbf{n}=34)\end{array}$ & $\begin{array}{l}\text { p value } \\
\text { between } \\
\text { groups }\end{array}$ \\
\hline Age (years) & $48.0(33.0 / 66.6)$ & $43.0(33.5 / 65.0)$ & $46.5(33.8 / 68.0)$ & 0.6 \\
M:F & $27: 4$ & $28: 5$ & $28: 6$ & \\
Neck size (cm) & $45.7(39.5 / 53.0)$ & $45.7(37.7 / 50.1)$ & $44.5(35.6 / 53.3)$ & 0.7 \\
$\begin{array}{l}4 \% \mathrm{SaO}_{2} \text { dip rate } \\
\text { per hour }\end{array}$ & $36.8(12.0 / 64.9)$ & $33.4(11.9 / 82.0)$ & $33.0(12.7 / 78.0)$ & 0.9 \\
ESS & $16.0(10.6 / 23.0)$ & $17.0(10.4 / 22.6)$ & $16.5(10.5 / 22.3)$ & 0.7 \\
MWT (min) & $19.4(1.4 / 40.0)$ & $19.5(2.9 / 40)$ & $15.7(2.1 / 40)$ & 0.8 \\
24 hour mean BP & $95.8(77.0 / 122.0)$ & $95.2(77.3 / 118.3)$ & $96.2(75.0 / 120.7)$ & 0.9 \\
SAQL score & $3.9(1.7 / 6.0)$ & $3.1(1.5 / 5.8)$ & $3.5(1.9 / 6.1)$ & 0.4 \\
\hline
\end{tabular}

ESS, Epworth Sleepiness Score; MWT, Maintenance of Wakefulness test; $\mathrm{SaO}_{2}$, oxygen saturation; SAQL, Sleep Apnea Quality of Life Index.

patients were randomised to one of three CPAP treatment groups: (1) autotitration pressure for 6 months; (2) autotitration pressure for 1 week followed by fixed pressure determined by the 95th centile pressure from the week's data; and (3) fixed pressure determined by an algorithm based on neck circumference and OSA severity, as previously described. ${ }^{22}$ Balanced randomisation was by means of a computer program (MINIM version 1.5, Evans S). The patients and the investigators carrying out the assessment studies were blind to their group allocation. One and 6 months after commencing CPAP the patients returned for further study assessments. Any patients who failed to attend their study visits were contacted by telephone to rearrange their appointment. If they could not be contacted or did not reply they were sent a reminder letter. Based on our previous two way studies on the treatment of OSA, this study was powered so that 30 patients in each group would have an $80 \%$ chance at the 5\% level of not missing a difference in ESS of 2.5 points between groups following treatment, a difference in MWT (OSLER) of 6 minutes between groups, or a difference in CPAP compliance of 1.4 hours per night. ${ }^{123}$

\section{Data analysis}

ESS, MWT (OSLER), 24 hour BP, AHI, usage, pressure, leak and self-reported health status scores (SF-36, SAQLI) were compared between the three groups. Statistical analysis was carried out using SPSS version 11.0. Non-parametric testing was performed using the Kruskal-Wallis test. The results are shown as median values ( 5 th/95th centile). Standard errors of the differences for key outcome measures were also calculated to provide confidence intervals on these differences.

\section{RESULTS}

\section{Patient characteristics}

Ninety eight patients were recruited to the study and randomised following their first study visit. The three groups were well matched at baseline (table 1 ) and had moderate to severe OSA (median $>4 \% \mathrm{SaO}_{2}$ dip rate 34.5 dips per hour, range 10.3-89.0).

The trial outline is shown in fig 1. Data were available 1 month after CPAP initiation for 92 patients and at 6 months for 86 patients. Six patients did not attend at 1 month, but two of these patients did attend at 6 months. Nine patients did not attend at 6 months. No data were entered for those who did not attend. Two patients stopped using their CPAP after 1 month, one because he could not tolerate it and one because he had lost weight and was no longer symptomatic from OSA. Both of these patients were in the group receiving 1 week of autotitration. These patients
633 patients started CPAP in Oxford, Jan 02-Mar 03. 98 patients recruited to study (ESS $>9$ and $>10>4 \% \mathrm{SaO}_{2}$ dips per hour on sleep study).

All attended for study visit 1, pre-CPAP

\section{$\checkmark$}

Patients randomized to CPAP treatment groups following

first study visit:

A. 6 months variable pressure $(n=31)$

B. 1-week variable pressure, then fixed pressure $(n=33)$

C. 6 months algorithm derived fixed pressure $(n=34)$

$\checkmark$

CPAP initiation

$\checkmark$

One week routine sleep clinic after CPAP initiation.

Downloaded CPAP information available to nurses.

Group B changed to fixed pressure on basis of

downloaded pressure data

\begin{tabular}{|l|l|}
\hline $\begin{array}{l}\text { Study visit } 2 \text { after one } \\
\text { month of CPAP }\end{array}$ & $\begin{array}{l}6 \text { did not attend (2 from } \\
\text { each group) }\end{array}$ \\
\hline $\begin{array}{l}\text { Study visit } 3 \text { after six } \\
\text { months of CPAP }\end{array}$ & $\begin{array}{l}9 \text { did not attend (group A: 3, } \\
\text { group B: 2, group C: 4). }\end{array}$ \\
\hline $\begin{array}{l}1 \text { in algorithm group } \\
\text { excluded as CPAP found to } \\
\text { be on variable pressure }\end{array}$ \\
$\begin{array}{l}2 \text { people withdrew as stopped } \\
\text { CPAP: } 1 \text { could not tolerate it, } \\
1 \text { lost weight (both group B) }\end{array}$ \\
\hline
\end{tabular}

Figure 1 Trial outline.

did not return at 6 months. Four patients were found to be not using their CPAP at their 6 month follow up because they felt better; their ESS and OSLER scores had also improved. Three of these were in the algorithm group and one was in the 1 week autotitration group.

\section{Outcome measures (ESS, MWT, SF-36, SAQLI)}

There was a highly significant improvement in all outcome scores in all the groups following treatment with CPAP. There was no significant difference between the groups in any of the outcome measures (table 2). The standard errors of the difference between groups were 1.1 for ESS, 2.8 min for MWT, and $4.4 \mathrm{~mm} \mathrm{Hg}$ for blood pressure. 


\begin{tabular}{|c|c|c|c|c|}
\hline & $\begin{array}{l}\text { Group 1: } \\
6 \text { months } \\
\text { autotitration }\end{array}$ & $\begin{array}{l}\text { Group 2: } \\
1 \text { week } \\
\text { autotitration }\end{array}$ & $\begin{array}{l}\text { Group 3: } \\
\text { Algorithm }\end{array}$ & $\begin{array}{l}\text { p value } \\
\text { between } \\
\text { groups }\end{array}$ \\
\hline \multicolumn{5}{|l|}{ ESS } \\
\hline Pre CPAP & $16.0(10.6 / 23.0)$ & $17.0(10.4 / 22.6)$ & $16.5(10.5 / 22.3)$ & 0.7 \\
\hline 1 month & $7.0(1.0 / 12.0)$ & $7.0(0 / 15.4)$ & $6.0(1.0 / 19.8)$ & 0.9 \\
\hline 6 months & $6.0(0.45 / 13.8)$ & $5.0(0 / 15.5)$ & $5.0(0.5 / 12.5)$ & 0.8 \\
\hline \multicolumn{5}{|l|}{ MWT (min) } \\
\hline Pre CPAP & $19.4(1.4 / 40.0)$ & $19.5(2.9 / 40)$ & $15.7(2.1 / 40)$ & 0.8 \\
\hline 1 month & $40.0(5.1 / 40.0)$ & $40.0(5.5 / 40.0)$ & $31.3(3.1 / 40)$ & 0.1 \\
\hline 6 months & $40.0(11.6 / 40.0)$ & $40.0(14.5 / 40)$ & $40.0(2.2 / 40)$ & 0.2 \\
\hline \multicolumn{5}{|c|}{ Mean BP $(\mathrm{mm} \mathrm{Hg})$} \\
\hline Pre CPAP & $95.8(77.0 / 122.0)$ & $95.2(77.3 / 118.3)$ & $96.2(75.0 / 120.6)$ & 0.9 \\
\hline $1 \mathrm{month}$ & $93.3(73.0 / 115.0)$ & $93.3(78.0 / 108.0)$ & $96.4(84.0 / 115.0)$ & 0.4 \\
\hline $\begin{array}{l}6 \text { months } \\
\text { SF-36 PCS }\end{array}$ & $99.6(77.3 / 119.0)$ & $96.7(82.7 / 119.0)$ & $96.4(73.3 / 114.3)$ & 0.5 \\
\hline Pre CPAP & $62.5(17.2 / 93.2)$ & $65.7(25.2 / 90.0)$ & $62.6(25.9 / 92.5)$ & 0.6 \\
\hline 1 month & $79.7(35.1 / 95.4)$ & $81.7(33.1 / 94.5)$ & $81.3(30.5 / 98.7)$ & 0.8 \\
\hline 6 months & $78.8(20.0 / 96.2)$ & $85.2(26.6 / 95.3)$ & $83.3(40.9 / 98.3)$ & 0.5 \\
\hline \multicolumn{5}{|l|}{ SF-36 MCS } \\
\hline Pre CPAP & $57.2(19.8 / 87.5)$ & $56.8(26.0 / 89.4)$ & $56.6(16.6 / 88.7)$ & 0.9 \\
\hline 1 month & $77.7(32.5 / 93.6)$ & $82.3(39.7 / 94.0)$ & $81.8(24.4 / 97.6)$ & 0.9 \\
\hline 6 months & $79.3(30.5 / 94.1)$ & $81.5(27.8 / 95.0)$ & $82.7(35.4 / 95.4)$ & 0.9 \\
\hline \multicolumn{5}{|l|}{ SF-36 EV } \\
\hline Pre CPAP & $25.0(6.0 / 74.0)$ & $30.0(0 / 78.0)$ & $27.5(3.8 / 72.5)$ & 0.9 \\
\hline 1 month & $65.0(30.0 / 87.5)$ & $60.0(24.0 / 90.0)$ & $60.0(23.3 / 100.0)$ & 0.9 \\
\hline 6 months & $67.5(19.0 / 82.8)$ & $67.5(35.0 / 94.9)$ & $60.0(42.0 / 94.0)$ & 1.0 \\
\hline \multicolumn{5}{|c|}{ Change in SAQLI } \\
\hline 1 month & $1.4(-3.2 / 4.3)$ & $1.5(-4.0 / 4.5)$ & $0.8(-5.4 / 3.7)$ & 0.2 \\
\hline 6 months & $1.6(-4.8 / 4.3)$ & $1.5(-5.6 / 4.7)$ & $1.4(-5.2 / 3.4)$ & 0.7 \\
\hline
\end{tabular}

\section{CPAP data (usage, mask leak, airway pressure)}

Table 3 shows the CPAP data downloaded from the machines from all the groups. The data are taken from the preceding 28 days at both 1 and 6 months in order to reflect the recent past. There was no significant difference between the three groups in terms of the hours of CPAP use per night, the percentage of nights used, mask leakage, or AHI. The standard error of the difference between the groups for CPAP use per night was 0.41 hours.
The median and 95th centile pressures shown were CPAP machine generated. There was a significant difference in the delivered CPAP pressures between the groups. The algorithm and 1 week autotitration groups both had fixed pressures delivered so their median and 95th centile pressures are the same. As the 6 month autotitration group received varying pressures, the median and 95th centile pressures are different. At 1 and 6 months the 95th centile CPAP pressures delivered in the 6 month and 1 week autotitration groups

\begin{tabular}{|c|c|c|c|c|}
\hline & $\begin{array}{l}\text { Group 1: } \\
6 \text { months } \\
\text { autotitration }\end{array}$ & $\begin{array}{l}\text { Group 2: } \\
1 \text { week } \\
\text { autotitration }\end{array}$ & $\begin{array}{l}\text { Group 3: } \\
\text { Algorithm }\end{array}$ & $\begin{array}{l}\text { p value } \\
\text { between } \\
\text { groups }\end{array}$ \\
\hline \multicolumn{5}{|c|}{ Median pressure $\left(\mathrm{cm} \mathrm{H}_{2} \mathrm{O}\right)$} \\
\hline 1 month & $9.5(6.4 / 12.8)$ & $11.1(8.2 / 14.3)$ & $9.8(7.7 / 13.0)$ & 0.001 \\
\hline 6 months & $9.7(6.4 / 11.7)$ & $11.5(3.2 / 14.3)$ & $10.0(7.8 / 12.5)$ & $<0.0001$ \\
\hline \multirow{2}{*}{\multicolumn{5}{|c|}{$\begin{array}{l}95 \text { th centile pressure }(\mathrm{cm} \\
\left.\mathrm{H}_{2} \mathrm{O}\right)\end{array}$}} \\
\hline & & & & \\
\hline 1 month & $10.8(8.7 / 15.8)$ & $11.1(8.9 / 14.3)$ & $9.8(7.7 / 13.0)$ & 0.001 \\
\hline 6 months & $11.6(9.1 / 14.6)$ & $11.5(3.2 / 14.3)$ & $10.0(7.8 / 12.5)$ & $<0.0001$ \\
\hline \multicolumn{5}{|c|}{ Hours used per night } \\
\hline 1 month & $5.3(0 / 7.3)$ & $4.3(0 / 7.12)$ & $4.7(0 / 8.3)$ & 0.27 \\
\hline 6 months & $5.49(0 / 7.5)$ & $4.9(0 / 7.2)$ & $4.0(0 / 8.3)$ & 0.23 \\
\hline \multicolumn{5}{|c|}{ Nights used (\%) } \\
\hline 1 month & $96.9(31.3 / 100)$ & $98.4(51 / 100)$ & $96.6(47 / 100)$ & 0.68 \\
\hline 6 months & $100(5 / 100)$ & $98.3(61 / 100)$ & $92.6(33 / 100)$ & 0.21 \\
\hline \multicolumn{5}{|l|}{$\mathrm{AHI}$} \\
\hline 1 month & $5.8(0.4 / 17.3)$ & $4.2(1.2 / 12.6)$ & $4.4(0.5 / 23.5)$ & 0.4 \\
\hline 6 months & $5.2(1.5 / 13.2)$ & $3.6(0.5 / 15.9)$ & $3.8(0.7 / 26.1)$ & 0.3 \\
\hline \multicolumn{5}{|c|}{ Median leak (I/s) } \\
\hline 1 month & $0.02(0 / 0.5)$ & $0.05(0 / 0.2)$ & $0.04(0 / 0.3)$ & 1.0 \\
\hline \multirow{2}{*}{\multicolumn{5}{|c|}{$\begin{array}{l}05^{\text {th }} \text { conthile leak }(\mathrm{l} / \mathrm{s})\end{array}$}} \\
\hline & & & & \\
\hline 1 month & $0.2(0 / 1.5)$ & $0.3(0 / 0.7)$ & $0.3(0 / 0.8)$ & 0.2 \\
\hline 6 months & $0.2(0 / 1.5)$ & $0.3(0 / 0.7)$ & $0.3(0 / 0.8)$ & 0.4 \\
\hline
\end{tabular}


were significantly higher than those delivered in the algorithm group. The median pressures were lowest in the 6 month autotitration group. Only one patient (who was in the I week autotitration group) had his CPAP pressure increased by the sleep nurses due to residual snoring.

\section{Telephone calls to sleep nurses}

There was no difference between the groups in terms of the number of extra calls or extra visits made to the sleep nurses because of CPAP problems (median 0 calls/visits per group, range $0-3)$.

\section{DISCUSSION}

We report the results of a double blind randomised trial of three different methods of determining and delivering the pressure during CPAP treatment for OSA. The three methods selected were chosen to represent those commonly used in clinical practice: (1) long term autotitration, (2) autotitration for 1 week with long term fixed pressure thereafter, and (3) an algorithm method of pressure determination. We opted to use 1 week autotitration in the second group as there is evidence that titration for 1 night is unreliable because of the considerable night to night variation in CPAP requirements. ${ }^{22}$ We did not have a titration polysomnography group as a recent study has established that the outcomes are no different from those on 1 night autotitration. ${ }^{24} 25$

The study directly compared the outcomes of the three groups over a 6 month period and looked at a comprehensive range of relevant outcome measures. Therapeutic CPAP was provided equally well by all three methods of CPAP initiation. The improvements in ESS and MWT were consistent with those found in other studies of patients with OSA started on CPAP treatment. ${ }^{12426}$ The patients were followed up for 6 months after CPAP initiation, so information regarding longer term outcomes including CPAP pressures and compliance was available. There was no difference between the three groups in terms of subjective and objective measures of sleepiness, 24 hour blood pressure, usage, AHI, and mask leakage. Self-reported health status measured by the SF-36 and SAQLI improved in all three groups, with no significant difference between them. SAQLI scores at 6 months had risen by a mean of 1.5. These figures are a little larger than those found in a recent study of CPAP in 288 patients with varying severities of OSA which reported mean increases of 0.87 in the SAQLI score 1 month after treatment. ${ }^{13}$

The CPAP pressures varied significantly between the groups. The median pressure in the 1 week autotitration group was significantly higher than in the other two groups, reflecting the fact that it was based on the 95th centile pressure after 1 week. The median pressure was lowest in the 6 month autotitration group, although the 95th centile pressure was higher than that of the algorithm group. Despite the differences in pressure, there was no difference in the outcome measures between the three groups which suggests that the lower pressure delivered in the 6 month autotitration and algorithm groups is adequate to improve AHI and reduce symptoms.

Although this study was not powered to look at changes in blood pressure with CPAP treatment, we noted that expected falls in blood pressure occurred following CPAP at 1 month (borderline significance) but returned to baseline levels at 6 months. There were no significant differences in blood pressure change between the three groups. A previous randomised controlled trial in OSA showed a significant fall in blood pressure following 1 month of CPAP, but there have been no controlled studies of the longer term effect of CPAP on blood pressure. ${ }^{27}$ We do not have information regarding pre-existing hypertension in our study patients or whether they were taking antihypertensive medication.
The autotitration CPAP machines used in this study cost about 30\% more than a simple fixed pressure CPAP machine. Since this study shows that long or short term autotitration confers no clinical advantage over fixed pressure determined by an algorithm, it can be concluded that algorithm methods of CPAP initiation probably represent an effective and economic option in the treatment of moderate to severe OSA. As the algorithm method of initiating CPAP avoids the need for CPAP titration, this represents a further economic advantage to this approach.

Our overall results can be compared with those from a recent large multicentre 12 week study by Masa et $a l^{24}$ in which 360 patients with OSA were randomised to receive CPAP by either conventional overnight polysomnographic titration to determine a fixed pressure, one night of home autotitration to determine a fixed pressure, or an algorithm derived pressure with subsequent adjustment if symptoms continued. There was no long term autotitration group. No significant differences were found between the groups at 12 weeks in terms of ESS, AHI, SF-36, or CPAP usage. This study did not, however, provide any objective measures of sleepiness and it could be argued that the data are subjective only. Differences may only emerge after the first 3 months of CPAP use, and other valid end points such as blood pressure, SAQLI scores and mask leakage were not measured.

In a single blind crossover trial Hukins ${ }^{25}$ gave patients with OSA 2 months of both fixed pressure CPAP and autotitrated CPAP. Both groups had diagnostic and treatment polysomnography to determine their required mask pressures before commencing CPAP. No significant differences were found in the main outcome measures-subjective sleepiness (ESS) and self-reported health status (SF-36) -between the two groups after treatment. Mean nightly usage was similar in the two treatment groups. These results are therefore essentially the same as those of our study. Those receiving CPAP via the autotitration mode reported significantly fewer side effects (as measured by visual analogue scales) than those receiving fixed pressure CPAP $(p=0.02)$. The numbers of patients studied was smaller than in our study $(n=46)$ and no objective measures of outcome such as MWT or blood pressure were used. Visual analogue scales have not been widely reported as an outcome measure of OSA, and they have not been compared with the validated SAQLI measure of self-reported health status specific to OSA which specifically takes account of side effects of treatment and overall impact on quality of life in the calculation of its final score.

Ayas et $a l^{28}$ performed a meta-analysis of all the available randomised trials comparing autotitrated CPAP with fixed pressure CPAP. Nine studies with a total of 282 patients were included. Autotitration CPAP showed no significant advantage over fixed pressure CPAP based on the outcome measures of AHI, ESS, and CPAP usage. All the studies determined the fixed CPAP pressure following titration polysomnography. The mean pressure was lower in the autotitration groups $\left(2.2 \mathrm{~cm} \mathrm{H}_{2} \mathrm{O}\right)$ than in the fixed pressure CPAP groups. Our results are not directly comparable because of our different methods of establishing the fixed CPAP pressure, but we found the median pressure in the 6 month autotitration group to be comparable to the algorithm determined pressure and lower than the median pressure in the 1 week autotitration group.

The results of all these studies, along with our own, show that long term autotitration CPAP has no clinical advantage over fixed pressure CPAP in patients with moderate to severe OSA. The results may be different in patients with milder OSA. It has been argued that there may be specific subgroups of patients in whom autotitration CPAP is more efficacious. A study by Massie et $a^{29}$ showed that, in patients requiring CPAP pressures of $>10 \mathrm{~cm} \mathrm{H}_{2} \mathrm{O}$ on initial treatment poly- 
somnography, their compliance was greater with autotitration CPAP than with fixed pressure CPAP (mean of 35 minutes more per night, $\mathrm{p}=0.005)$. Overall, 95 th centile pressures were lower with autotitration $\left(9.2 \vee 10.9 \mathrm{~cm} \mathrm{H}_{2} \mathrm{O}\right.$, $\mathrm{p}<0.001)$. Some components of the SF-36 showed a significant improvement in the autotitration group compared with the fixed CPAP group, but improvements in ESS did not differ between the two groups. We performed a subgroup analysis on the quarter of patients receiving the highest pressures in each group and found no significant difference between the groups in their CPAP usage.

In conclusion, we have shown little or no difference in several clinically relevant outcomes between patients with OSA treated with CPAP by three different methods. We did not detect any advantage of long term autotitration CPAP with the Autoset Spirit over fixed pressure CPAP. A simple algorithm approach to defining the fixed pressure required is no worse than fixed pressure established following a week with an autotitrating CPAP machine.

\section{ACKNOWLEDGEMENTS}

The authors are grateful to all the patients who took part in the study and to the staff of the Oxford Sleep Unit for all their practical help, particularly Eileen Smith and Amanda Cooper.

\section{Authors' affiliations}

S D West, D R Jones, J R Stradling, Sleep Unit, Oxford Centre for Respiratory Medicine, Churchill Hospital, Headington, Oxford OX3 7ப, UK

ResMed UK provided part financial support for the purchase of CPAP machines for the study but was not involved in its design or analysis. D Jones was supported in part by a Helen Bearpark Scholarship from the Australasian Sleep Association and by the Sleep Apnoea Trust Association (UK).

None of the authors has any conflict of interest.

\section{REFERENCES}

1 Jenkinson C, Davies RJ, Mullins R, et al. Comparison of therapeutic and subtherapeutic nasal continuous positive airway pressure for obstructive sleep apnoea: a randomised prospective parallel trial. Lancet 1999;353:2100-5.

2 American Sleep Disorders Association Standards of Practice Committee. Practice parameters for the indications for polysomnography and related procedures. Sleep 1997;20:406-22.

3 Planes C, D'Ortho MP, Foucher A, et al. Efficacy and cost of home-initiated Auto-nCPAP versus conventional CPAP. Sleep 2003;26:156-60.

4 Stradling JR, Barbour C, Pitson DJ, et al. Automatic nasal continuous positive airway pressure titration in the laboratory, patient outcomes. Thorax 1997; 52:72-5.

5 Berry RB, Parish JM, Hartse KM. The use of auto-titrating continuous positive airway pressure for treatment of adult obstructive sleep apnea. An American Academy of Sleep Medicine review. Sleep 2002;25:148-73.
6 Konermann M, Sanner BM, Vyleta M, et al. Use of conventional and selfadjusting nasal continuous positive airway pressure for treatment of severe obstructive sleep apnea syndrome: a comparative study. Chest 1998;113:714-8.

7 Gagnadoux F, Rakotonanahary D, Martins De Araujo MT, et al. Long-term efficacy of fixed CPAP recommended by Autoset for OSAS. Sleep 1999;22:1095-9

8 Stradling JR, Hardinge M, Smith DM. A novel, simplified approach to starting nasal CPAP therapy in OSA. Respir Med 2004;98:155-8.

9 Hoffstein V, Mateika S. Predicting nasal continuous positive airway pressure. Am J Respir Crit Care Med 1994;150:486-8.

10 Fitzpatrick MF, Alloway CE, Wakeford TM, et al. Can patients with obstructive sleep apnea titrate their own continuous positive airway pressure? Am J Respir Crit Care Med 2003;167:716-22.

11 Flemons WW, Vazquez JC. Home titration of nasal CPAP is safe and effective: results of a randomized trial. Am J Respir Crit Care Med 2001;161:A27.

12 Bennett LS, Langford BA, Stradling JR, et al. Sleep fragmentation indices as predictors of daytime sleepiness and nCPAP response in obstructive sleep apnea. Am J Respir Crit Care Med 1998;158:778-86.

13 Whitelaw WA, Brant RF, Flemons WW. Clinical usefulness of home oximetry compared with polysomnography for assessment of sleep apnea. Am J Respir Crit Care Med 2005;171:188-93.

14 Johns MW. A new method for measuring daytime sleepiness: the Epworth sleepiness scale. Sleep 1991;14:540-5.

15 Bennett LS, Stradling JR, Davies RJO. A behavioural test to assess daytime sleepiness in obstructive sleep apnoea. J Sleep Res 1997;6:142-5.

16 Priest B, Brichard C, Aubert G, et al. Microsleep during a simplified maintenance of wakefulness test. A validation study of the OSLER test. Am J Respir Crit Care Med 2001;163:1619-25.

17 Krieger AC, Ayappa I, Norman RG, et al. Comparison of the maintenance of wakefulness test to a behavioral test-the Oxford sleep resistance (OSLER) test in the evaluation of wakefulness. J Sleep Res 2004; 13:407.

18 Jenkinson C, Stradling J, Petersen S. Comparison of three measures of quality of life outcome in the evaluation of continuous positive airways pressure therapy for sleep apnoea. J Sleep Res 1997;6:199-204.

19 Flemons WW, Reimer MA. Development of a disease-specific health-related quality of life questionnaire for sleep apnea. Am J Respir Crit Care Med 1998; 158:494-503.

20 Flemons WW, Reimer M. Measurement properties of the Calgary Sleep Apnea Quality of Life index. Am J Respir Crit Care Med 2002;165:159-64.

21 Flemons WW, Reimer M. The Calgary Sleep Apnea Quality of Life index (SAQLI) manual. Alberta, Canada: University of Calgary, 1996.

22 Stradling JR, Hardinge M, Paxton J, et al. Relative accuracy of algorithmbased prescription of nasal CPAP in OSA. Respir Med 2004;98:152-4.

23 Jenkinson C, Davies RJ, Mullins R, et al. Long-term benefits in self-reported health status of nasal continuous positive airway pressure therapy for obstructive sleep apnoea. Q J Med 2001;94:95-9.

24 Masa JF, Jimenez A, Duran J, et al. Alternative methods of titrating continuous positive airways pressure. Am J Respir Crit Care Med 2004;170:1218-24.

25 Hukins C. Comparative study of autotitrating and fixed-pressure CPAP in the home: a randomized, single-blind crossover trial. Sleep 2004;27:1512-7.

26 Engleman HM, Martin SE, Kingshott RN, et al. Randomised placebo controlled trial of daytime function after continuous positive airway pressure (CPAP) therapy for the sleep apnoea/hypopnoea syndrome. Thorax 1998;53:341-5.

27 Pepperell JCT, Ramdassingh-Dow S, Crosthwaite N, et al. Ambulatory blood pressure following therapeutic and sub-therapeutic nasal continuous positive airway pressure for obstructive sleep apnoea: a randomised prospective parallel trial. Lancet 2002;359:204-10.

28 Ayas NT, Patel SR, Malhotra A, et al. Auto-titrating versus standard continuous positive airway pressure for the treatment of obstructive sleep apnea: results of a meta-analysis. Sleep 2004;27:249-53.

29 Massie CA, McArdle N, Hart RW, et al. Comparison between automatic and fixed positive airway pressure therapy in the home. Am J Respir Crit Care Med 2003;167:20-3. 